\title{
Assessment of kitchen waste generated in a maternity hospital: a case study in Brazil
}

Leonardo de Lima Moura, Claudio Fernando Mahler and Heitor Mansur Caulliraux

Universidade Federal do Rio de Janeiro

mourampb4@gmail.com; cfmahler@gmail.com; heitor.caulliraux@gmail.com

\begin{abstract}
Healthcare waste management (HCWM) is at problem in many developing countries. One of the main steps to implement a proper HCWM process is knowledge of the amount and composition of material generated. There are rare studies of the contribution of kitchen waste to the total mass of non-hazardous waste generated by hospitals in the world. This paper reports a diagnosis of waste generation by the kitchen of a maternity hospital in the state of Rio de Janeiro, Brazil. Using the method established by the World Health Organization (WHO), non-hazardous wastes of all sectors were weighed for seven consecutive days in July and August, 2015. The average kitchen waste generated was $92.77 \mathrm{~kg}$.day ${ }^{-1}$ and $76,73 \mathrm{~kg}^{-d a y}{ }^{-1}$, respectively, corresponding to $43.65 \%$ and $46.44 \%$ of the total mass of general waste produced in the period, although there was no positive correlation between the generated mass of kitchen waste and the number of meals prepared and served. We concluded that kitchen waste poses a considerable challenge to HCWM, mainly involving temporary internal storage, external storage and container cleaning, as well in the physical conditions of the workers that transport the waste.
\end{abstract}

Keywords: Kitchen waste, non-hazardous waste, healthcare waste, healthcare waste management, maternity hospital. 


\section{Introduction}

The poor management of healthcare waste $(\mathrm{HCW})$ is a problem in many developing countries because they are already dealing with population growth and increasing demand for health services due to the improved quality of life and longer life expectancy. These countries have gaps in different stages of management of HCW, especially with regard to segregation and final disposal.

Healthcare waste management (HCWM) practices vary from country to country or region to region within countries, since they depend on several factors such as the socioeconomic conditions, human and financial resources available and the existing legislation. Therefore, an important step for implementation of better HCWM is knowledge of the amount of HCW generated and its composition. This is a particularly glaring problem in Brazil, where little information is available even in richer states like São Paulo and Rio de Janeiro.

According to the Brazilian Association of Solid Waste and Cleaning Companies (ABRELPE), about 41.9\% of municipalities in the Southeast region of the country still do not give any special treatment to HCW, often depositing ti in dumps or landfills mixed with municipal solid waste (ABRELPE, 2014).

In other developing countries, the situation is very similar with regard to shortage of data about HCW generation and composition. This has encouraged research to diagnose waste in hospitals in several countries, such as: China (Royan et al., 2010; Zhang et al., 2013), Ethiopia (Haylamicheal et al., 2011; Debere et al., 2013; Tadesse and Kumie, 2014; Tesfahun et al., 2014), Iran (Askarian et al., 2004; Abed-Elmdoust and Kerachian, 2012; Sartaj and Aragbol, 2015), India (Patil and Shekdar, 2001; Pant, 2012), Portugal (Dias-Ferreira et al., 2015) and Turkey (Alagoz and Kocasoy, 2008; Eker et al. , 2010).Regarding HCW diagnosis in Brazilian hospitals, there is a lack of recent studies, although Gunther and Moreira (2012) and Alves et al. (2014) analyzed HCW generation in health centers, while Soares et al. (2013) conducted a review of the use of life cycle assessment (LCA) for choosing the best form of HCW treatment .

Da Silva et al. (2005) studied health facilities in southern Brazil and found that the HCW quantity generated was one of the hardest figures to determine since many factors influence its generation, and in addition hospitals in general do not perform any kind of measurement of the amount and composition of HCW generated, making it necessary to consult collection companies for estimates. More recently, Aduan et al. (2014) surveyed the health and environmental authorities at the municipal, state and federal levels regarding generation of $\mathrm{HCW}$ in sixteen hospitals in Vitória (ES), finding a complete lack of data.

As for the factors cited by Da Silva et al. (2005) that can influence the HCW generation in health facilities, Debere et al. (2013) cited the number of available beds, number of patients treated daily, types of medicine practiced, seasonality and the existence of HCW segregation at the source or not.

Aware of the importance of HCW knowledge about generation and composition for the proper management and mitigation of negative impacts on public health and the environment, in 2014 the World Health Organization (WHO) introduced a new version of a practical guide aimed to improve HCWM, mainly in developing countries.

In this guide, knowledge of the quantity and types of HCW generated is mentioned as extremely relevant to the safe final disposal process. These data also allow the health establishment's managers to estimate the number of necessary containers, storage areas, type of transport and most appropriate treatment. These numbers also enable calculating the generation rates per unit or sector, enabling optimization of the HCWM system, environmental impact assessment and especially analysis of potential for recycling. 
The highlight of the WHO on HCW recyclability is due to the fact that between $75 \%$ and $90 \%$ of waste generated by health care providers is comparable to municipal solid waste (MSW) and is generated mainly in the administrative, kitchen, cleaning and maintenance areas.

The importance of kitchen waste generation in health facilities has been reported by authors such as Mattoso and Schalch (2001), who in a study performed in a Brazilian hospital with 400 beds in São Paulo, estimated that about $13 \%$ of the total mass generated came from the kitchen. However, the authors emphasized that this amount was likely much larger, since these wastes were not precisely quantifiable because they were contained in plastic bags along with other general waste.

Internationally, Patwary et al. (2009), in an HCW study of hospitals and clinics in Bangladesh over a period of five months, observed that the contribution of kitchen waste was on average respectively $50.46 \%$ and $45.42 \%$ of total generated. They noted that unless this is mixed with infectious waste, it is not hazardous, so it does not require a specific treatment and some can be reutilized.

In a more recent study conducted in three Brazilian hospitals, based on the WHO method, Tivirolli et al. (2010) found that the kitchen was the sector that most contributed to the total mass of HCW generated, with values ranging from $17.3 \%$ to $31.1 \%$

Trying to analyze the causes related to the large generation of kitchen waste in health facilities, Sonnino and McWilliam (2011) analyzed the generation of kitchen waste in three hospitals located in Wales and found a strong correlation between the quality of the meal service and amount of food wasted. In addition, the authors pointed out that the quantities of prepared meals are often overestimated compared to the number of patients and staff allocated ot provide meals.

In a more focused study for estimation of meals served, Dias-Ferreira et al. (2015) emphasized that the generation of this type of waste is three times higher in hospitals than in schools and restaurants/coffee shops. At the same time, the authors highlighted the scarcity of data for hospital kitchen waste in the various countries of Europe.

Due to lack of studies analyzing the contribution of kitchen waste to the total mass of non-hazardous waste generated and also to examine the possible impact thereof on HCWM of a hospital, we analyzed the HCW generation of a maternity hospital in the state of Rio de Janeiro, with a focus on kitchen waste.

\section{Materials and methods}

According to the most recent data from the Brazilian Institute of Geography and Statistics (IBGE), the state of Rio de Janeiro has an estimated population of 16,550,024 inhabitants, making it the third most populous state in Brazil. Regarding health facilities, according to the National Health System (SUS), the state has 19,085 health establishments, of which 160 are specialized hospitals like the one examined here.

The hospital is a state reference in public maternity care for low and medium complexity pregnancies. It has 98 beds, of which 70 are in the general ward, 12 are in the pre-birth, birth and post-birth (PPP) area, 8 are in the intensive care unit (ICU) for neonates and the remaining beds are distributed among post-anesthesia recovery assistance to neonates and the surgical center (SC).

The survey was conducted in three stages: the first stage occurred in February and March, the second from 613 July and the third from 3-9 August 2015. 


\subsection{First stage}

Non-participant observation was carried out in the HCW sector by monitoring the collection activitis for four weeks in order to learn the management practices adopted and analyze the impact of kitchen waste on overall HCWM activities. This monitoring consisted of listening, observing and recording the collectors' activities.

The information obtained was documented by notes indicating the day and the collector of that day and also through photo documentation supporting the information obtained. In parallel with this, a documentary analysis of the Healthcare Waste Management Plan (PHCWM) adopted by the institution was performed to note possible differences between what was called for in the plan and what was actually performed by employees. Finally, information on the collection company contracted by the hospital was obtained from the database of the state environmental agency, which requires such companies to obtain registration.

\subsection{Second and third stage}

The second stage and third stage consisted of measuring (weighing) HCW generated and was carried out for seven consecutive days from 6 to 12 July and again from 3 to 9 August 2015, except for ambulatory waste, which was weighed for five consecutive days, since this sector does not work on weekends. To perform this step, we used the WHO's method and because of this, HCW generated in each sector was separated by the labels used to identify the container to be used in each sector during the collection step.

Regarding the number of samples taken per day and its timing, there was no interference of the researcher at the collection stage, with the collector only being asked to inform the researcher of the moment of collection so he could accompany the operation.

All HCW bags of all sectors, except for the kitchen waste generated in the period of 7-19h, were weighed daily for seven consecutive days on an electronic scale with $200 \mathrm{~kg}$ capacity in the in the waste shelter after end of internal collection, while kitchen waste was weighed in the container itself.

Data were recorded daily in standard tables and then compiled for the PSPP statistical tool to generate the descriptive statistics (mean, standard deviation, coefficient of variation, maximum mass generated, minimum mass generated).

At the end of seven days, the administrative manager was questioned about the number of meals prepared and number of meals served, based on information provided by the outsourced nutrition company.

Furthermore, based on the number of meals prepared and served, PSPP was applied to determine the possible correlation between the number of meals and the amount of kitchen waste generated by calculating Pearson's coefficient.

\section{Results and discussion}

\subsection{Kitchen description}

The hospital kitchen is coordinated by an outsourced company that is responsible for estimating the number of meals and preparing and serving them. Each employee, patient and visitor can have four meals a day: breakfast, lunch, snack and dinner. The breakfast usually is composed of milk, coffee or juice and bread. Lunch and dinner are usually salads, rice, beans and meat, which can be replaced by eggs, along with fruit and a commercial sweet as dessert. 
To serve inpatients, there is a maid service that is responsible for preparing and distributing meals in the various sectors. After the end of the meals, these employees return to each sector to collect food waste.

During the reporting period, due to continuous complaints from employees about repeat of the food offered as snack, a wider range was offered, with only juice, coffee or milk remaining fixed.

\subsection{Descriptive statistical analysis of kitchen waste}

Table 1 presents the statistical analysis of kitchen waste generated in each sector from 6 to 12 July and 3 to 9 August: Table 1- Descriptive analysis of kitchen waste in the period from 6 to July 12

Table 1 - Statistical analysis of kitchen waste

\begin{tabular}{|c|c|c|c|c|c|c|c|c|}
\hline Kitchen & $\begin{array}{l}\text { Containers } \\
\text { collected }\end{array}$ & $\begin{array}{l}\text { Mean } \\
\text { (kg) }\end{array}$ & $\begin{array}{l}\text { Standard } \\
\text { deviation }\end{array}$ & $\begin{array}{l}\text { Coefficient } \\
\text { of variation } \\
(\%)\end{array}$ & $\begin{array}{l}\text { Minimum } \\
\text { weighed } \\
\text { mass }(\mathrm{kg})\end{array}$ & $\begin{array}{l}\text { Maximum } \\
\text { weighed } \\
\text { mass (kg) }\end{array}$ & $\begin{array}{c}\text { Total } \\
\text { generated } \\
\text { mass }(\mathrm{kg})\end{array}$ & $\begin{array}{l}\text { Contribution of } \\
\text { kitchen waste in } \\
\text { general waste }\end{array}$ \\
\hline 6 to 12 July & 12 & $\begin{array}{r}44.76 \\
\pm 5.33\end{array}$ & 18.48 & 41.29 & 8.15 & 80.65 & 537.10 & $43 \%$ \\
\hline $\begin{array}{l}3 \text { to } 9 \\
\text { August }\end{array}$ & 14 & $\begin{array}{r}44.36 \\
\pm 6,82\end{array}$ & 25.51 & 57.51 & 16.75 & 99.25 & 621.05 & $45 \%$ \\
\hline
\end{tabular}

In relation the kitchen waste, in the period from July to August there was an increase in the generation. This increase may be related to the change in the external collection company, since the company in July usually collected the waste at 13:00 h, removing the kitchen waste from that sector itself, which made that part of kitchen waste not usually heavy. In August, the new external collection company began collecting only the waste that was in the external shelter around 5:30 and because of this most of the kitchen waste began to be stored in the external shelter.

Regarding the minimum masses recorded in July and August, the respective values for kitchen waste were $8.15 \mathrm{~kg}$ and $16.75 \mathrm{~kg}$. In both cases, although the bags were full, they contained mainly cardboard mixed with food. These observations indicate problems in the training process both of kitchen workers, who put cardboard mixed with food, and collectors who forwarded the material for recycling.

As for the maximum mass, there was a range from $80 \mathrm{~kg}$ to nearly $100 \mathrm{~kg}$ between July and August. This was a constant target of complaints from internal hospital collectors and the outsourced company, which often threatened no longer to take kitchen containers since the excess weight would pose an ergonomic risk, particularly of back and joint pains.

It can also be seen from the table that the contribution of kitchen waste in general waste was $45 \%$ on average. This value cannot be compared with any HCW research because this study analyzes the contribution of kitchen waste in the total mass of general waste, not all types of HCW.

Table 2 presents some characteristics of other studies indicating kitchen waste contribution: 
Table 2 - Analysis of the characteristics of different HCW research

\begin{tabular}{|c|c|c|c|}
\hline \multirow{3}{*}{$\begin{array}{l}\text { Authors } \\
\text { Mattoso } \\
\text { and Schalch } \\
\text { (1991) }\end{array}$} & \multicolumn{3}{|c|}{ Research characteristics } \\
\hline & Sampling Period & Type of scales utilized & Problems reported by the authors \\
\hline & $\begin{array}{l}\text { Weighing during every day of the } \\
\text { week over two months }\end{array}$ & No description & $\begin{array}{l}\text { Kitchen and cafeteria wastes could not be } \\
\text { quantified because they were disposed together } \\
\text { with the general waste. As a result, there was } \\
\text { only the quantification of organic waste from the } \\
\text { wards }\end{array}$ \\
\hline $\begin{array}{l}\text { Patwary et } \\
\text { al. (2009) }\end{array}$ & $\begin{array}{l}\text { Weighing for three days in of each } \\
\text { health institution }\end{array}$ & No description & $\begin{array}{l}\text { Kitchen waste was mixed with infectious waste, } \\
\text { so the authors had to segregate them first and } \\
\text { then weigh them. }\end{array}$ \\
\hline $\begin{array}{l}\text { Tivirolli et } \\
\text { al. (2010) }\end{array}$ & $\begin{array}{l}\text { Weighing for seven consecutive } \\
\text { days in four campaigns in the first } \\
\text { hospital, three campaigns in the } \\
\text { second and five in the third hospital }\end{array}$ & $\begin{array}{l}\text { The authors reported they used } \\
\text { two scales: one with a capacity } \\
\text { of } 12.5 \mathrm{~kg} \text { and another with } \\
\text { capacity of } 150 \mathrm{~kg}\end{array}$ & $\begin{array}{l}\text { Hospitals did not have any kind of segregation, so } \\
\text { the authors used the parameters established by the } \\
\text { WHO to estimate the amount of HCW types. }\end{array}$ \\
\hline
\end{tabular}

Analyzing the research presented in the table, it can be observed that there is considerable variation between the sampling times performed by the authors, ranging from three days to two months per institution, as in the study Mattoso and Schalch (1991). It is important to mention that the study Patwary et al. (2009) was conducted in over 60 institutions, only two of them hospitals, while Mattoso and Schalch (1991) carried out their work in a single hospital.

Regarding the types of scales used, only Tivirolli et al. (2010) described this aspect, specifying the use of scales of different accuracies, while Mattoso and Schalch (1991) and Patwary et al. (2009) did not address the issue.

However, the authors reported the same problem with regard to quantifying the kitchen waste, as absence or failure in segregation. In the reported cases of Tivirolli et al. (2010) Patwary et al. (2009), not segregation was observed, which led to the mixture of kitchen waste with infectious material. In the present study, since kitchen waste was disposed directly by the sector in a specific temporary storage area, there was a greater facility to quantify the waste.

Is worth mentioning that the waste from inpatient meals was often discarded by the patients themselves in general or infectious trash cans in the rooms, meaning some of the kitchen waste wound up being counted in other sectors. .

\subsection{Number of meals prepared $x$ number of meals served}

Based on the information supplied by the hospital's outsourced meal service company, we analyzed the differences between the numbers of prepared meals and served meals during July and August.

Figure 1 shows the number of meals prepared and served from 6 to 12 July. 


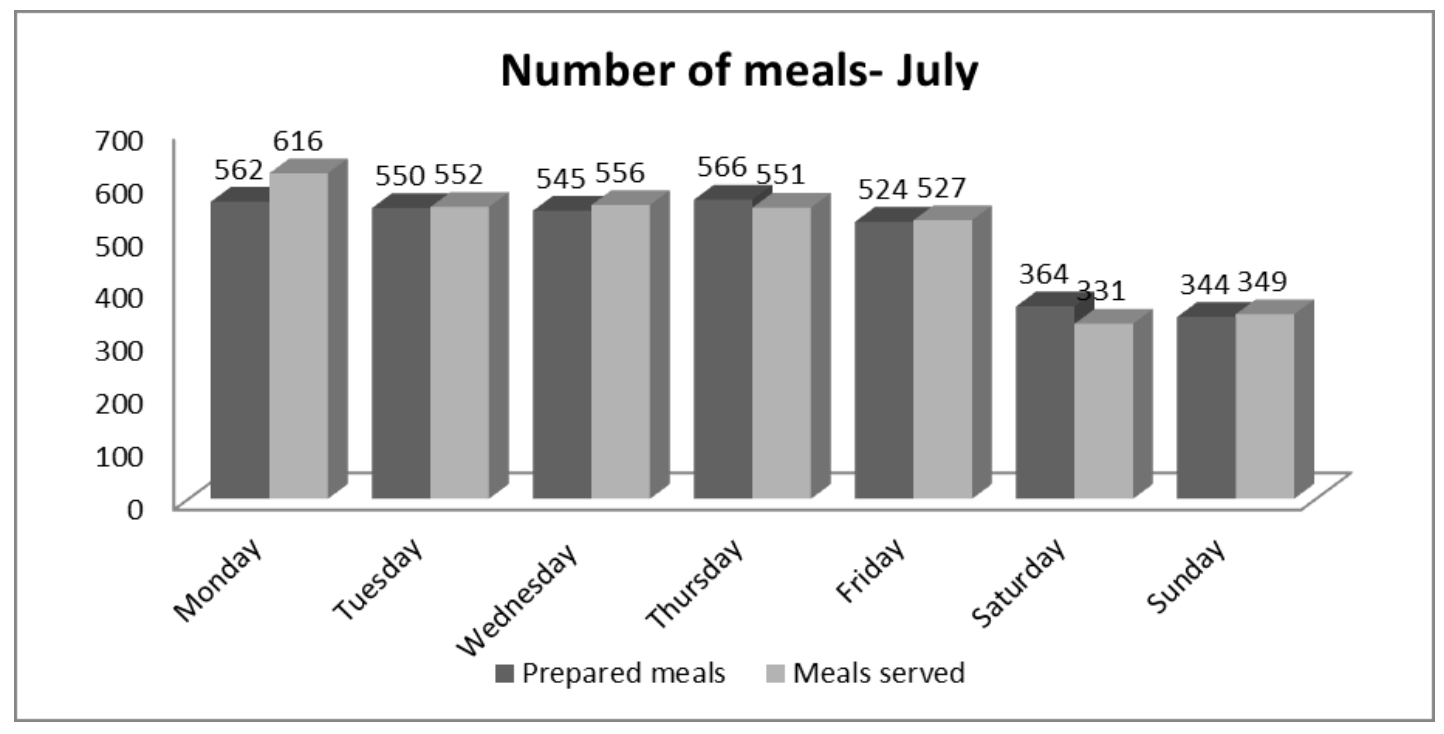

Figure 1 - Number of meals in July

Figure 2 shows the number of meals prepared in served from 3 to 9 August.

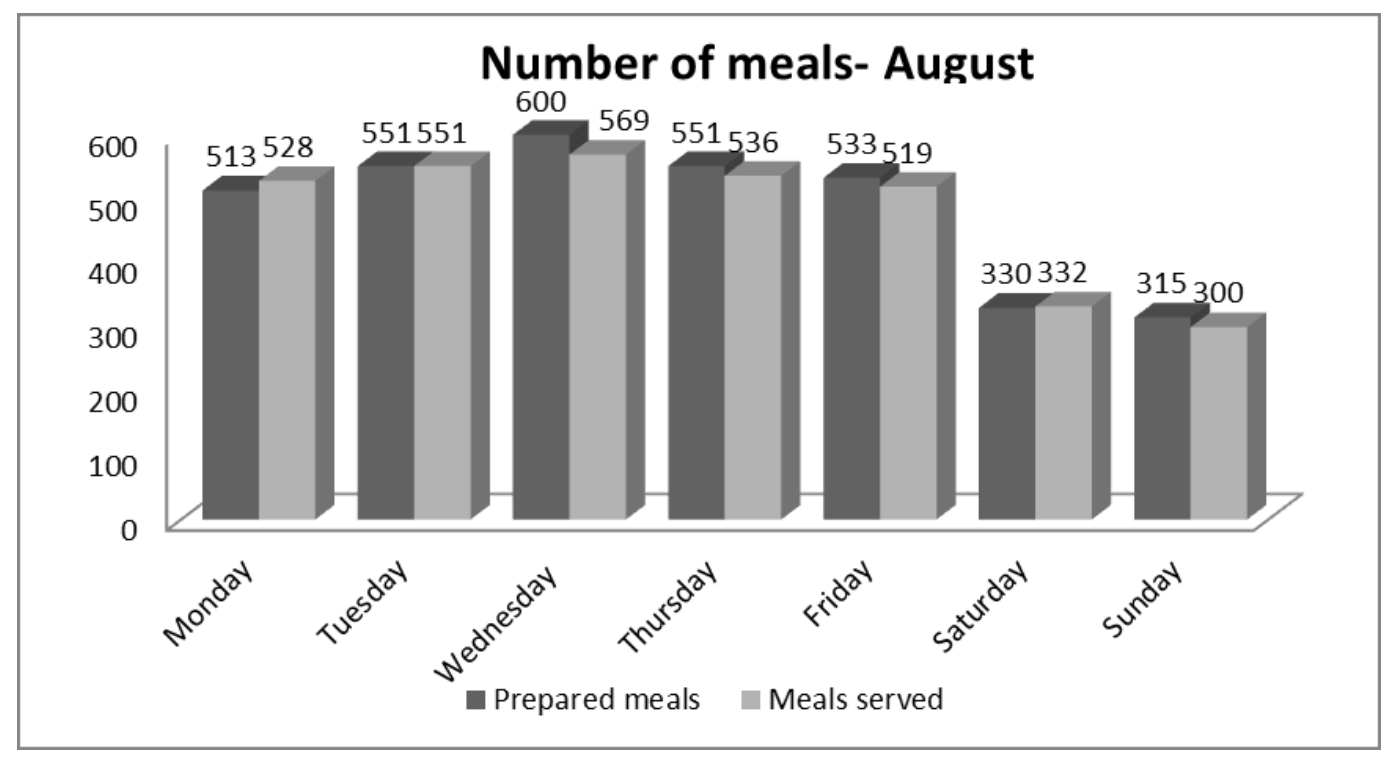

Figure 2- Number of meals in August

Analyzing Figures 1 and 2, differences can be noted between the number of meals prepared and those actually served on nearly all days, often occurring a higher number of prepared meals than those served. This finding agrees with that of Sonnino \& McWillian (2011), who found that the quantities of prepared meals are often overestimated compared to the number of patients and staff.

Another factor which shows that preparing meals is overrated is that on certain days, especially on Mondays in both months was observed more served meals than prepared, and on Monday July is difference was 54 meals and August 15 meals, and how these days was not observed any shortage of meals that as indicated by the authors Sonnino and McWillian (2011), the kitchen must produce much larger amount of food than the amount informed. 


\subsection{Correlation between the number of meals prepared and the generation of kitchen waste}

To analyze a possible correlation between the number of meals prepared and the generation of kitchen waste, we calculated Pearson's correlation coefficient based on data for prepared meals and total daily mass of kitchen waste. The results are reported in Table 4

Table 4 - Correlation between the number of meals prepared and the generation of kitchen waste

\begin{tabular}{l|l|l|l}
\hline Sector & Analyzed coeficiente & $\begin{array}{l}\text { Prepared meals from 6 to } \\
\text { 13 July }\end{array}$ & $\begin{array}{l}\text { Prepared meals from 3 to 8 } \\
\text { August }\end{array}$ \\
\hline \multirow{2}{*}{ Kitchen } & & 3455 & 3393 \\
\cline { 2 - 4 } & Pearson's coeficiente & 0.74 & 0.89 \\
\cline { 2 - 4 } & Sig (2-tailed) & 0.06 & 0.08 \\
\hline
\end{tabular}

With regard to Table 4, it can be noted that the coefficients were 0.74 and 0.89 in July and August, respectively. These values are close to 1 , indicating a positive correlation between the total mass generated and the number of prepared meals. However, the values of the significance test were above the value 0.05 , meaning this correlation is not significant.

\subsection{Correlation between the number of meals served and the total mass of kitchen waste generated.}

We subsequently analyzed the possible correlation between the number of meals served and the mass of waste generated in the kitchen. These results are presented in Table 5.

Table 5 - Correlation between the number of meals served and the generation of kitchen waste

\begin{tabular}{l|l|l|l}
\hline Sector & Analyzed coefficient & Meals served from 6 to 13 July & Meals served from 3 to 8 August \\
\hline \multirow{2}{*}{ Kitchen } & & 3482 & 3335 \\
\cline { 2 - 4 } & Pearson's coefficient & 0.67 & 0.88 \\
\cline { 2 - 4 } & Sig (2-Tailed) & 0.09 & 0.09 \\
\hline
\end{tabular}

Analysis of the number of meals served and the total mass of kitchen waste generated again revealed correlation values near 1, indicating a positive correlation between the number of meals served and a total mass of kitchen waste. However, again the results of the significance test were above 0.05 , meaning the correlations were not significant. 


\subsection{Impact of kitchen waste on HCWM}

The period of non-participant observation of HCWM practices revealed several impacts of kitchen waste, mainly on temporary internal storage, external storage and cleaning of containers.

The kitchen waste is stored outside of the sector in open containers. The presence of exposed residues can attract vectors such as flies, ants and cockroaches. Moreover, the lack of standardization of the collection time causes the accumulation of waste in the containers, causing some waste to spill over on the floor, which can also attract vectors.

Another factor that is worth mentioning is the excess waste stored in containers which can cause the breakage of the containers used. The main result of container damage is the spread of liquid waste in the area outside the hospital, especially during collection activities, which attracts various types of vectors like flies, cockroaches and ants.

Kitchen waste typically occupies six containers during the period from 7:00-19:00 $\mathrm{h}$, since the area intended for the storage of general waste is too small for the amount of waste generated. Because of that, HCW is usually placed out of container, against Brazilian law. Also, because of breakage of containers, there is a possibility of leakage of liquid from kitchen waste. The consequence is that the external cleaning activity becomes futile since there is continuous drainage of liquid waste under the floor, also drawing vectors.

Finally, due to excess waste in each kitchen bag, many fall rupture and the contents end up being dumped in the containers at the time of external collection. The result is that at the time of cleaning, many of these kitchen waste containers are dumped directly on the ground in the outdoor area. Since many of these wastes are not swept and collected by the collectors, they end up accumulating in the outer area of the shelter, constituting another source of vectors.

\section{Conclusion}

From the diagnosis of kitchen waste accomplished at the maternity hospital, we observed a significant contribution of the kitchen in the general waste, representing approximately $47.5 \%$ of the non-hazardous waste. Kitchen waste has a substantial impact on the healthcare waste management examined. It is the main source of complaints from collectors due to overweight bags and represents unnecessarily higher costs for HCWM. Moreover, kitchen waste attracts many vectors that are unacceptable in a hospital, a place that should prioritize orderliness and cleanliness. When these wastes were handled improperly, they damaged containers and occupied a large part of external shelter, negatively impacting the correct storage of other general waste.

Analyzing the factors that could influence the generation of kitchen waste, we did not observe any significant correlation between the number of prepared and served meals and the total mass of waste generated, which indicates that other factors may be influencing this generation, especially the fact that the number of hospital meals needed is usually overestimated by the kitchen service. This is an important issue, because the scraps from hospital meals as well as other kitchen waste, which could be reused in composting processes, are routed together with other non-hazard waste to landfills. 


\section{References}

Abed-Elmdoust, Kerachian N. R., 2012. Regional hospital solid waste assessment using the evidential reasoning approach. Science of the Total Environment, 441, 67-76.

ABELPRE - Associação Brasileira de Empresas de Limpeza e Resíduos Sólidos (Brazilian Association of Solid Waste and Cleaning Companies), 2014. Panorama dos Resíduos Sólidos 2014 (Solid Waste Panorama 2014). ABRELPE, São Paulo.www.abelpre.org.br

Aduan, S. A., Braga, F.S, Zandonade, E., Salles, D., Cussiol, N.A.M., Lange, L.C., 2014. Evaluation of hospital health waste of Group A in hospitals of Vitória (ES), Brasil. Engenharia Sanitaria e Ambiental, 19(2), 133-141.

Alagöz, A. Z., Kocasoy, G., 2008. Determination of the best appropriate management methods for the healthcare wastes in Istanbul. Waste Management, 28, 7, 1227-1235.

Askarian, M., Vakili, M., Kabir, G., 2004. Results of a hospital waste survey in private hospitals in Fars province, Iran. Waste management, 24, 4, 347-352.

Brasil. Ministry of Health. National Health Surveillance Agency., 2004. Board Resolution - RDC n 306, de 7 de dezembro de 2004. Official Diary of the Union, Dec.10.2004

Da Silva, C. E., Hoppe, A. E., Ravanello, M. M., Mello, N., 2005. Medical wastes management in the south of Brazil. Waste Management, 25(6), 600-5.

Debere, M. K., Gelaye, K. A., Alamdo, A. G.,Trifa, Z. M., 2013. Assessment of the health care waste generation rates and its management system in hospitals of Addis Ababa, Ethiopia, 2011. BMC Public Health, 13(1), 28.

Dias-Ferreira, C., Santos, T., Oliveira, V.,2015. Hospital food waste and environmental and economic indicators-A Portuguese case study. Waste Management, 46, 146-154

Eker, H. H., Bilgili, M. S., Sekman, E., \& Top, S., 2010. Evaluation of the regulation changes in medical waste management in Turkey. Waste Management \& Research, 28(11), 1034-1038.

Haylamicheal, I. D., Dalvie, M. A., Yirsaw, B. D., Zegeye, H. A., 2011. Assessing the management of healthcare waste in Hawassa city, Ethiopia. Waste Management \& Research, 29(8), 854-862.

Mattoso, V. D.B, Schalch, V., 2001. Hospital waste management in Brazil: A case study. Waste management \& research, 19, 6, 567-572

Pant, D., 2012. Waste management in small hospitals: trouble for environment. Environmental monitoring and assessment, 184(7), 4449-4453.

Patwary, M. A., O’Hare, W. T., Street, G., Elahi, K. M., Hossain, S. S., \& Sarker, M. H.,2009. Quantitative assessment of medical waste generation in the capital city of Bangladesh. Waste management, 29(8), 23922397.

Ruoyan, G., Lingzhong, X., Huijuan, L., Chengchao, Z., Jiangjiang, H., Yoshihisa, S., ... \& Chushi, K., 2010. Investigation of health care waste management in Binzhou District, China. Waste Management, 30(2), 246-50.

Sartaj, M., Arabgol, R., 2015. Assessment of healthcare waste management practices and associated problems in Isfahan Province (Iran).Journal of Material Cycles and Waste Management, 17, 1, 99-106. 
Sonnino,R.,Mcwilliam, S., 2011. Food waste, catering practices and public procurement: A case study of hospital food systems in Wales. Food Policy, 36, 6, 823-829.

Tadesse, M. L., Kumie, A., 2014. Healthcare waste generation and management practice in government health centers of Addis Ababa, Ethiopia. BMC public health, 14, 1, 1221.

Tesfahun, E., Kumie, A., Legesse, W., Kloos, H., \& Beyene, A., 2014. Assessment of composition and generation rate of healthcare wastes in selected public and private hospitals of Ethiopia. Waste Management \& Research, 0734242X14521683.

Tivirolli, K., Tivirolli, S. C., Luz, P. C. D., Fujino, L. B. V., Shinzato, M. P., Skowronski, J., ... \& Hess, S. C, 2010. Management in three public hospitals of Mato Grosso do Sul , Brazil. Revista Brasileira de Promoção a Saúde, 23(1), 213-220.

Zhang, H. J., Zhang, Y. H., Wang, Y., Yang, Y. H., Zhang, J., Wang, Y. L., Wang, J. L., 2013 Investigation of medical waste management in Gansu Province, China. Waste Management \& Research, 31(6), $655-9$.

World health organization, 2014. Safe health-care waste management. Principles for achieving safe and sustainable management of health-care waste. Geneva. Available at: http://www.who.int/water sanitation_health/medicalwaste/hcwprinciples/en/>. Consulted on: June 30, 2015. 